\title{
Smartphonisasi Agama: Transformasi Perilaku Beragama Perempuan Urban di Era Digital
}

\author{
Mite Setiansah \\ Jurusan Ilmu Komunikasi FISIP Universitas Jenderal Soedirman, Purwokerto
}

\begin{abstract}
ABSTRAK
Sebelum teknologi digital, termasuk smartphone menjadi bagian dari kehidupan sehari-hari masyarakat, aktivitas beragama lebih merupakan bagian dari urusan privat daripada publik. Hampir semua agama mengajarkan bahwa ritual keagamaan baik yang dilakukan secara vertikal antara manusia dengan Tuhannya maupun secara horisontal antara manusia dengan manusia hendaknya dilakukan semata-mata untuk mendapatkan pahala dari Tuhan. Pamer keshalehan menjadi semacam tabu untuk dilakukan. Namun kini, smartphone telah melahirkan kultur baru dimana perilaku beragama tidak lagi merupakan urusan pribadi manusia dengan Tuhannya, namun juga menjadi bagian dari aktivitas yang biasa dipajang di ruang display media, khususnya smartphone. Praktek beragama kemudian mengalami smartphonisasi ketika karakteristik dan logika smartphone kemudian telah turut membentuk praktek beragama di era digital ini. Menggunakan teknik wawancara, observasi, dan dokumentasi penelitian ini mencoba mengungkapkan bagaimana transformasi perilaku béragama di kalangan perempuan urban.
\end{abstract}

Kata Kunci: Agama, Smartphone, Perilaku, Perempuan

\section{Pendahuluan}

Possamai (2005: 35) menyebutkan bahwa, "what is meant by religions today is no longer what it once was." Agama saat ini berbeda dengan agama yang kita pahami sebelumnya. Pendapat tersebut setidaknya menjelaskan bahwa telah terjadi transformasi di dalam praktek beragama saat ini. Agama tidak lagi dipahami seperti dahulu. Dalam ajaran tradisional, ritual keagamaan adalah sésuatu yang tidak layak untuk dipertanyakan, untuk dibantah, untuk dijalankan di luar pakem, ataupun untuk dijadikan sebagai konsumsi publik. Agama adalah bagian dari privasi yang tidak layak untuk diungkit ataupun diperbincangkan di ruang publik.

Namun demikian, seiring dengan kèmajuan teknologi informasi dan digital dengan kulturnya yang khas, praktek beragama pun mengalami transformasi. Praktek beragama menjadi sangat lentur dan bisa disesuaikan dengan karakter setiap media, termasuk smartphone. Untuk mendapatkan informasi agama dan melakukan ritual agama, orang tidak perlu lagi datang ke mesjid atau gereja, tidak perlu lagi membuka kitab-kitab suci yang tebal, atau mendengarkan ceramah yang panjang. Melalui smartphone orang bisa lebih mudah terkoneksi dengan internet dan dapat mencari informasi tentang agama apapun dengan leluasa. Melalui smartphone orang bisa menyebarkan ajaran agama, maupun menerima informasi keagamaan. Melalui smartphone mereka bisa merepresentasikan identitas religiusnya masing-masing. Bahkan, di smartphone, mereka bisa melakukan ritual keagamaannya secara langsung. Terkait dengan perilaku beragama yang demikian itu, Possamai (2005: 47) menjelaskan bahwa, "Religion in our postmodern times - wether we like or not - is definitely part of consumer culture." Ditambahkannya 
pula bahwa, "in a consumer society that hold people together, not as a citizens but as consumers, the majority of people are more interested in a religious quick $f i x$ than follow a long journey of spiritual pain/gain" (Possamai, 2005: 41). Dengan kata lain, dalam masyarakat konsumen, untuk beragama pun orang lebih mengedepankan unsur kepraktisan dan serba instant.

Praktek beragama melalui smartphone ini tidak dapat dilepaskan dari kehadiran internet dan media digital yang kehadirannya telah menimbulkan banyak perdebatan terkait dengan implikasinya terhadap agama. Berbagai ulasan tentang media baru dan agama setidaknya dapat ditemukan dalam Understanding the Relationship between Religion Online and Offline in Networked Society (Campbell, 2011); Religion on The Internet: Community and Virtual Existence (Foltz dan Foltz, 2003); The Mediatization of Religion, $A$ Theory of the Media as an Agent of Religious Change (Hjarvard, 2006) dan lain-lain. Ragam tema kajian tersebut berkisar pada implikasi kehadiran internet terhadap institusi agama maupun perilaku beragama individu. Hasil review terhadap sejumlah riset tentang agama dan internet/ on line setidaknya memberikan gambaran bahwa kehadiran internet telah membawa transformasi ke dalam kehidupan beragama, mulai dari konstruksi identitas religius, pola penyebaran informasi keagamaan, hingga keterkaitan antara praktek beragama di dunia online dengan offline-nya. O'Leary (dalam Hackett, 2006: 67) mengatakan bahwa, "the advent of the internet has been as revolutionary for religious growth and dissemination as was the invention of the printing press."

Kehadiran smartphone dalam kehidupan sehari-hari masyarakat saat ini, telah membuat akses masyarakat terhadap internet menjadi semakin mudah. Orang semakin mudah mengakses apapun dari internet termasuk bisa mengunggah apapun ke internet melalui smartphone. Ritual beragama yang sebelumnya lebih bersifat pribadi dan transenden pun kini mengalami perubahan signifikan. Perilaku beragama kini tidak ubahnya seperti smartphone itu sendiri, menjadi bagian dari gaya hidup. Fenomena demikian, kemudian mendorong peneliti untuk menelusuri lebih jauh bagaimana kehadiran smartphone membawa proses transformasi di dalam perilaku beragama perempuan urban. Perempuan urban dipilih dengan pertimbangan bahwa mereka merupakan pangsa pasar dan kelompok pengguna smartphone yang cukup besar. Secara kultural, posisi perempuan yang kerap kali berada dalam situasi yang subordinat juga menjadi pertimbangan tersendiri di dalam penelitian ini.

\section{Metode Penelitian}

Penelitian ini dilaksanakan dengan menggunakan metode etnografi, baik secara online (virtual ethnography) maupun offline. Pengumpulan data dilaksanakan dengan menggunakan teknik observasi, dokumentasi, dan wawancara kepada 5 (lima) orang informan, yang merupakan perempuan urban dengan variasi status pernikahan, pekerjaan, dan agama. Analisis data dilakukan dengan menggunakan teknik analisis data interaktif dimana proses analisis berjalan secara siklus sejak pengambilan data hingga penarikan simpulan.

\section{Pembahasan}

\section{Ketika Smartphone Mentransformasi Logika Agama}

$\mathrm{T}$ adalah seorang suster medior di Purwokerto, artinya dia telah menjalani kehidupan sebagai biarawati sekitar dua puluh lima tahun. Sebagai seorang suster yang hidup di biara, $T$ memaparkan bahwa kehidupan sehari-harinya sudah sangat teratur. Jam berapa harus do'a, jam berapa harus memberikan pelayanan, jam berapa boleh menonton televisi dan sebagainya. Ia juga terikat oleh kultur biara dengan segala kelengkapannya, sehingga ketika ada yang berbeda, maka hal tersebut dengan segera akan menjadi 
sorotan. Begitu juga ketika teknologi smartphone masuk ke dalam kehidupan mereka yang sudah terpola sedemikian rupa itu. Prasangka akan gaya hidup konsumtif dan perilaku yang melanggar etika langsung mengemuka. Resistensi terhadap teknologi smartphone terutama datang dari para suster senior. Namun daya penetrasi smartphone ternyata sangat kuat kuat hingga kemudian smartphone kini telah menjadi bagian dari keseharian para suster terutama di level medior dan junior.

Kami di sini kan tidak seperti yang lain, di sini kami memiliki batasanbatasan tertentu. Tidak banyak suster yang bisa memiliki fasilitas seperti smartphone. Seperti saya, saya memakai smartphone ini karena pemberian dari umat yang pernah saya layani. Ini juga saya gunakan setelah saya mendapat ijin dari pimpinan komunitas. Karena memang handphone saya yang lama sudah rusak saya dibolehkan memakainya. Kalau membeli sendiri tidak mungkin. Tapi sekarang banyak suster junior yang juga menggunakan smartphone, biasanya diberikan oleh keluarganya sebagai hadiah ketika mereka menyelesaikan pendidikan susternya. (Sr. T, 3 Januari 2015)

T memaparkan bahwa pada awal smartphone memasuki kehidupan biara, banyak prasangka dan kecurigaan yang ditujukan kepada penggunanya.

Kita itu kan biasanya cuma buka HP kalo di kamar..kalo di rumah di luar kamar kita gak buka HP kecuali memang jam istirahat..atau malam udah selesai acara..selesai doa penutup ada juga yang bawa HP keluar...tapi ada juga suster yang udah lekat banget dengan HPnya sampe ke kapel juga dibawa..kalo ditanya ngapain kamu bawa HP...ini kan ada doa di sini...di situlah kita baru tahu ternyata bisa download doa-doa. Ketika di sharing kita semua jadi tahu, jadi gak mempersoalkan lagi. Saya juga ikut download..karena doa jadi lebih praktis. Kita tidak perlu lagi bawa buku-buku tebal, semua tinggal download saja $1 \mathrm{x}$ selanjutnya bisa dipake terus. (Sr. $\mathrm{T}, 3$ Januari 2015)

Hingga tataran ini, salah satu aspek penting yang menjadi pertimbangan mengapa praktek beragama di smartphone banyak dilakukan orang adalah alasan kepraktisan. Praktis identik dengan mudah dan cepat. Berbeda dengan praktik beragama konvensional yang membutuhkan waktu lebih lama, ritual yang lebih panjang, dan tidak selalu sesuai dengan minat ataupun kebutuhan spiritual pengikutnya, melalui smartphone seseorang bisa memilih sendiri topik apa yang dicari, bisa mengendalikan waktu kapan dia ingin "menghadiri" sebuah kajian atau ibadah dan bahkan bisa menyesuaikan praktek ritual keagamaannya. Jika seorang suster saja bisa beralih media, dari membaca buku doa yang tebal menjadi hanya mengklik satu ikon buku doa di smartphone maka tidak menjadi sesuatu yang aneh jika pengguna smartphone lainpun banyak yang melakukan praktek beragama serupa. Seperti yang dikatakan oleh $\mathrm{E}$ berikut yang merupakan seorang dosen sebagai berikut

Saya tipe orang yang disuruh duduk manis seharian ngaji saya bisa tapi ada kalanya dalam 1 tahun saya tidak menyentuh al quran juga pernah...sekarang saya hanya menyimpan al quran pdf. di galnot saya, yang bisa saya baca sewaktu-waktu, misalnya di perjalanan. Biasanya kalo baca buku di kendaraan saya suka pusing, tapi dibawa baca al quran Alhamdulillah gak pusing. (E, 3 Januari 2015)

Keputusan Suster T ataupun E, untuk turut mengadopsi praktek beragama melalui smartphone menunjukkan bahwa praktek mediatisasi agama telah menemukan salah satu perwujudannya. Dikatakan oleh Stig 
Hjarvard (2006: 1) bahwa, "Mediatization: religion is increasingly being subsumed to the logic of the media, both in terms of institutional regulation, symbolic content and individual practices. Mediatisasi agama terjadi ketika agama kemudian dijalankan dengan menggunakan logika media. Praktis, singkat, menarik, sesuai selera dan sebagainya kemudian menjadi logika baru praktek beragama. Ketika agama sudah dijalankan dengan logika media, mediatisasi agama kemudian dapat dikenali dari karakteristik lembaga, produk keagamaan maupun ritual keagamaan yang diasumsikan akan memiliki karakter yang tidak jauh berbeda dengan komoditas media lainnya. Logika media yang kerap bekerja menggunakan logika waktu pendek, yang serba cepat, serba singkat telah memunculkan ritual beragama dengan logika yang kurang lebih sama.

Mediatisasi agama sangat jelas terlihat dalam media massa mainstream seperti televisi dan internet. Bagaimana televisi membuat beragam program yang dilabeli sebagai program religi, dari mulai sinetron religi, ceramah keagamaan hingga pemilihan da'i atau ustadz yang semua dikemas dengan logika media. Harus menarik, menghibur, memiliki daya jual, dan tentu saja cepat dan praktis. Jauh berbeda dengan proses konvensional yang harus ditempuh seseorang untuk bisa berada dalam status yang sama. Mediatisasi telah menimbulkan pemaknaan akan agama yang dangkal, hanya ada di permukaan. Itulah agama yang banal.
Pada faktanya, tidak hanya media massa yang melakukan komodifikasi atas agama, bahkan tidak jarang lembaga agama sendiri juga memproduksi beragam artefak berlabelkan agama yang dapat dimiliki oleh umatnya. "All religious groups produce commodities, or put positive values in some commodities, that can be bought by religious consumer" (Possamai, 2005: 47). Makanan dan minuman yang diidentikkan dengan agama tertentu, pakaian, hingga pesan semacam SMS Tauhid pada masa handphone atau mobile phone booming merupakan bebebrapa contoh komoditas yang diproduksi oleh institusi agama tertentu.

Dalam konteks smartphone, mediatisasi agama juga banyak tampak pada teks-teks yang diklaim sebagai simbol religius. Menampilkan kutipan ayat suci atau hadist di display picture (DP) atau mengupload foto aktivitas keagamaan di instagram, atau menuliskan kutipan ayat suci di status, dan lain sebagainya, seolah sudah memenuhi syarat untuk dikatakan melakukan syiar atau dakwah sebagaimana yang dikatakan oleh beberapa informan. Memasang DP berisi sebuah kalimat yang di sana tercantum nama Ali bin Abu Tholib misalnya, seolaholah sudah membuat pemasang DP yakin dengan kebenarannya. Tanpa menelusuri lebih jauh apakah tulisan itu benar berasal dari Ali bin Abu Tholib, paman sekaligus sahabat nabi, atau sesungguhnya tulisan itu dibuat oleh seseorang yang tidak diketahui identitasnya.
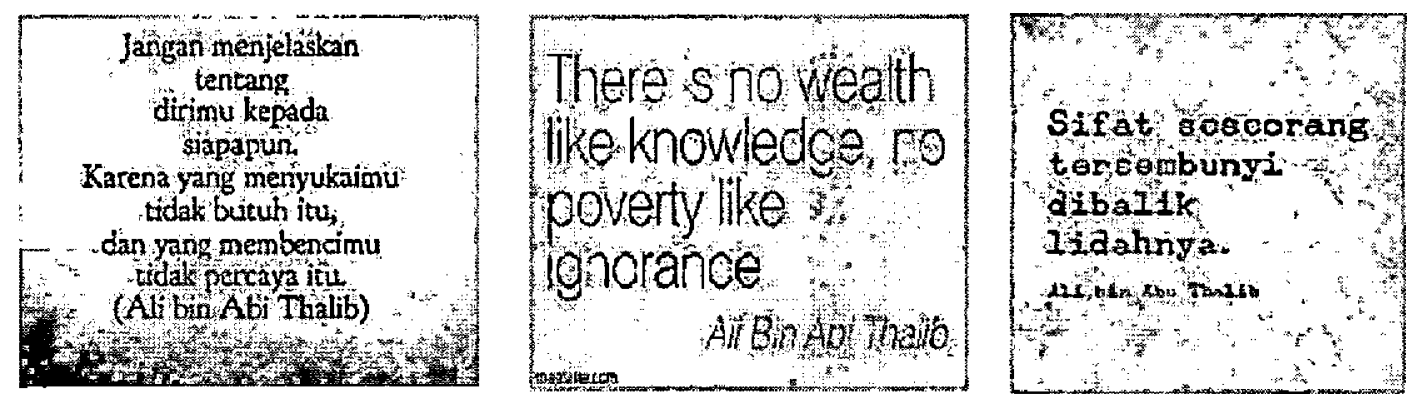

Gb. 1 Beberapa kutipan kata-kata Ali Bin Abi Thalib yang kerap muncul di display picture smartphone maupun media sosial 
Hal yang sama terjadi ketika pengguna smartphone menyebarkan pesan siaran (broadcast) berisi uraian panjang lebar tentang halal haram sesuatu, atau tentang peristiwa atau harihari besar dalam kalender Islam, namun jelas sekali pengirim pesan itu sendiri tidak memahami pesan yang dia kirimkan. Sebagai contoh, seseorang mengirim broadcast memberitahukan tentang akan jatuhnya nisfu sya'ban dan menganjurkan untuk saling meminta maaf. Sering terjadi adalah broadcast itu dikirimkan bukan pada bulan Sya'ban. Bahkan pengirim pesan tidak mengerti sama sekali tentang hukum nisfu syaban di dalam Islam. Namun sekali lagi logika waktu pendek media telah membuat mereka sekedar mengirim broadcast dan tidak lagi melakukan recheck atas informasi yang mereka terima dan sebarkan. Pada titik ini, praktek beragama melalui smartphone dapat dikatakan telah menjelma menjadi sebuah simulakrum. Agama dipahami hanya berdasarkan copy atas copy tanpa diketahui realitas sesungguhnya seperti apa. Salah seorang informan, S, seorang istri shalaffy, mengatakan bahwa pernah dalam sehari ia menerima sekitar enampuluh broadcast dari 1800-an kontak yang ada di smartphonenya. Banyak di antaranya merupakan broadcast yang berisi informasi "keagamaan" hanya saja menurutnya tidak semua broadcast itu benar. Oleh karena itu, ketika dia melihat ketidakbenaran itu kemudian menjadi tersebar massif karena fasilitas smartphone, dia kemudian juga akan menggunakan smartphonenya untuk meng-counter broadcast yang menurutnya salah tersebut.

Mencermati fenomena mediatisasi agama tersebut, maka konsep tentang budaya populer kemudian dapat pula dimunculkan. Agama dan budaya populer kini telah menjadi dua hal yang saling bertalitemali dengan erat. Mudah ditemukan tokoh-tokoh agama yang mengekspresikan dirinya dalam karakteristik budaya populer, seperti ustad-ustad muda yang kerap muncul di televisi dan kemudian dijuluki sebagai ustad gaul. Demikian pula komodifikasi agama telah banyak mewujud dalam beragam bentuk artefak media massa populer seperti lagu, sinetron, buku dan sebagainya. Artefak itu kemudian banyak menarik perhatian ummat karena dianggap lebih sesuai dengan karakteristik masyarakat dan mampu menjawab permasalahan keagamaan secara lebih sederhana dibandingkan dengan ajaran agama atau kitab agama konvensional. Possamai (2005: 20) menjelaskan hal tersebut sebagai berikut, "some people appear to practice religion/ spirituality by creatively reusing the artefacts of contemporary mass-mediated culture e.g. images, stories, and songs from cable and broadcast television, radio, Zines rather than following the meaning offered by religious institutions."

Ketika diterapkan dalam praktek beragama melalui smartphone, artefak keagamaan tersebut dengan mudah pula ditemukan, khususnya dalam bentuk beragam display picture yang memuat tulisan maupun simbol-simbol keagamaan. Tulisan-tulisan tentang do'a syukur, do'a mohon dimudahkan segala urusan, do'a mohon perlindungan, do'a untuk orang tua, do'a mohon rejeki dan keselamatan menjadi tulisan atau katakata favorit untuk dimuat di display picture pengguna smartphone.

Ketika ditelisik lebih jauh, penggunaan beragam artefak religi di smartphone ternyata dilakukan dengan beragam alasan pula. Mulai dari tujuan syiar/ dakwah, pencitraan, hingga sekedar ungkapan perasaan karena apa yang tercantum dalam status atau tulisan di display picture tersebut dirasakan memiliki kesejalanan dengan permasalahan atau peristiwa yang mereka hadapi.

\section{Praktek Beragama di Smartphone, dari Pencitraan Hingga Pembentukan Habitus}

Praktis, cepat, biaya murah, hasil maksimal adalah beberapa logika yang mendasari praktek penggunaan smartphone. Segera setelah smartphone booming, tiba-tiba banyak orang yang 
menjadi tampak lebih religius dari sebelumnya. Untuk menjadi sosok orang yang religius orang tidak perlu lagi mengeluarkan tenaga ekstra, waktu, dan juga biaya yang banyak untuk membeli buku-buku keagamaan, membacanya hingga tuntas, dan kemudian mendiskusikan dan menyebarluaskannya dalam forum-forum pengajian. Mereka juga tidak perlu biaya ekstra untuk membeli baju dan berdandan rapi, untuk kemudian datang ke gereja mendengar khotbah yang materinya ditentukan oleh pendetanya. Mereka juga tidak perlu menjadi ustad atau pendeta untuk bisa menyampaikan ajaran agamanya masing. Cukup sering-sering browsing, upload foto ketika sedang umrah/ haji di instagram, sering memasang display atau profile picture religius, menuliskan kutipan ayat-ayat kitab suci, atau menyebarkan broadcast religius, mengabarkan bahwa kita baru menghadiri pengajian, menulis status seusai sholat tahajjud dan sholat dhuha, maka citra religius pun bisa diperoleh.

Praktek menampilkan identitas religius semacam itu setidaknya diakui $\mathbf{S}$ sebagai hal yang biasa ia lakukan. S yang merupakan seorang penjual online, tidak hanya menampilkan foto diri dengan jilbabnya yang panjang namun juga kerap menampilkan kutipan ayat suci al Qur'an ataupun hadist sebagai status di smartphonenya. S mengaku bahwa dengan praktek seperti itu di smartphone, ia kemudian sering dijuluki sebagai ustadzah dan motivator oleh temantemannya, dan dia bangga dengan identitas tersebut. Baginya pengakuan religius terhadap dirinya menjadi penting untuk pencitraan dirinya sebagai penjual online yang kerap bertransaksi hanya berdasarkan kepercayaan. Identitas religius diyakininya akan meningkatkan kepercayaan konsumen terhadap dirinya.

$$
\text { Praktek konstruksi identitas }
$$

religius yang dilakukan $\mathbf{S}$ setidaknya sejalan dengan pendapat Gee (dalam Moulin, 2013: 4) bahwa, "Identity can be defined as 'what kind of person' someone is recognised as, or presents themselves as, in a given circumstance." 'Orang seperti apa' dapat terjawab melalui pengakuan orang lain terhadap seseorang atau presentasi diri orang tersebut. $\mathbf{S}$ ingin orang lain mengenalnya sebagai sosok religius, maka dia pun melakukan praktek keagamaan di smartphone, yang dalam hal ini menjadi media bagi $S$ untuk merepresentasikan dirinya. "Religius identity refers to the identification of an individual with a religious tradition" (Moulin, 2013:4). Pada tataran ini, kultur virtual di smartphone telah memberikan peluang bagi penggunanya untuk mengelola identitas diri sesuai dengan keinginannya.

Terlepas dari adanya kepentingan lain, seperti pencitraan dan konstruksi identitas, peluang menjalankan praktek beragama di smartphone tetap dapat dimaknai sebagai sebuah alternatif dari praktek beragama mainstream selama ini. Diakui atau tidak, disadari atau tidak, banyak praktek beragama konvensional yang tidak menyediakan pilihan bagi umatnya selain sekedar mengikuti dan menerimanya sebagai sebuah kebenaran esensialis yang tidak layak untuk dipertanyakan ulang. Akibat yang terjadi, tidak jarang praktek keagamaan dilakukan sebagai sebuah keterpaksaan dan semakin sulit dilakukan di tengah kesibukan yang semakin mengikat. Maka tidak heran jika dari hari ke hari semakin banyak rumah ibadah yang sepi dari jemaahnya, semakin banyak kitab suci yang terselip berdebu di rak buku. Dalam kondisi masyarakat yang demikian, smartphone kemudian menjadi semacam media alternatif untuk melakukan praktek beragama dengan lebih mudah.

Smartphone memberikan akses yang sangat luas menuju informasi agama yang tidak terbatas. $M$ yang seorang pendeta mengakui bahwa kini dia hampir tidak pernah lagi membawa kertas atau buku ketika sedang mempersiapkan atau menyampaikan khotbah. Sepanjang gadgetnya ada bersamanya, $M$ merasa tenang. $M$ mengatakan bahwa semua materi khotbah, sudah tersedia di gadgetnya tersebut. $\mathrm{S}, \mathrm{E}, \mathrm{M}$, dan $\mathrm{T}$ menggunakan smartphone mereka untuk mencari informasi keagamaan sesuai kebutuhan mereka. Informasi bisa diperoleh melalui searching ke situs-situs agama, maupun dengan bergabung dalam grup-grup tertentu, seperti yang dilakukan 
E. E menggunakan smartphone-nya untuk bergabung dengan grup ESQ. Di grup itu ia bisa mendapatkan postingan atau kutipan keagamaan yang menurutnya penting dan menginspirasi bagi dirinya.

Di samping sebagai instrument pendukung kegiatan beragama, smartphone juga menjadi lokus dari ritual keagamaan itu sendiri (on smartphone religion). Bahkan beragama melalui media smartphone kini menjadi gaya hịdup baru di kalangan para pengguna smartphone. Menyimpan aplikasi kitab suci di smartphone android atau tablet kini sudah lazim dilakukan termasuk oleh para informan. Mereka meyakini bahwa dengan menyimpan aplikasi tersebut mereka bisa membaca kitab. itu sewaktuwaktu, kapan saja dan dimana saja seperti yang diungkapkan Sr. $\mathrm{T}$ berikut, "sekarang untuk berdoa kita tidak perlu lagi membuka buku-buku brever yang tebal, semua sudah ada di smartphone."

Bukan hanya aplikasi kitab suci yang dipasang di smartphone. Banyak perempuan yang juga bergabung dalam grup-grup pengajian atau kajian virtual.

Baca quran di aplikasi quran android, pasang aplikasi radio kajian, ikut grup-grup kajian tertentu juga, jadi dapat materimateri yang aktual. Yaa kegiatan keagamaan lebih enak yang konvensional laah, kalau kajian bisa dengar langsung, bisa tanya jawab langsung tapi kajian di smartphone jadi bisa melengkapi saat gak bisa melakukan secara langsung misal lagi dalam perjalanan, tetep . bermanfaat banget, bisa tanya jawab juga dengan ustad meskipun lewat BBM. (R, 9 Desember 2014)

Hingga tataran ini, tampak bahwa smartphone telah menjelma menjadi media pembentuk habitus beragama dalam kehidupan sehari-hari penggunanya. $S$ bahkan ikut bergabung dengan grup Odoj (One day one juz) untuk memastikan bahwa dirinya akan membaca al quran setiap hari. ODOJ adalah komunitas virtual yang mengkoordinir dan mengkondisikan anggotanya sedemikan rupa sehingga mereka akan secara konsisten membaca 1 juz al Quran setiap hari. Komunitas itu tersebut dikelola oleh admin yang membagi anggota ke dalam grup-grup yang masing-masing terdiri dari 30 orang. Admin akan membentuk grup yang diberi nomor identitas/ nomor urut grup. Setiap hari tiap anggota diwajibkan selesai (kholas) membaca al qur'an minimal 1 juz dan melaporkannya kepada admin. Bila berhalangan akan dilelang kepada anggota lainnya atau dapat diganti dengan membaca terjemahan atau mendengarkan murrotal sesuai dengan juz yang ditugaskan. Dengan demikian, diharapkan setiap hari grup itu akan khatam membaca al qur'an.

Pembiasaan membaca al Qur'an yang coba dibangun melalui grup ODOJ terkadang juga mendorong anggotanya ke arah konstruksi identitas religius sebagaimana yang diuraikan di awal subbab ini. Banyak anggota ODOJ yang mencantumkan identitas grup ODOJ mereka di profil smartphone atau media sosial mereka. Mereka akan menuliskan nama diikuti nomor urut ODOJnya. Dengan demikian, siapapun yang melihat akan mengetahui bahwa mereka adalah anggota ODOJ, yaitu orang yang membaca 1 juz al Qur'an setiap hari. Meski demikian tidak semua anggota ODOJ mempublikasikan identitas ODOJ nya, S adalah salah satunya. Ia menjelaskan alasannya sebagai berikut:

Orang-orang shalaffy banyak yang gak setuju odoj, baca quran kenapa kudu lapor-laporan segala, semua anggota jadi tahu kalo baca quran, kesannya riya... tapi buat aku kalo gak gitu kapan mau konsisten baca quran..jadi ada yang ngingetin kalo lagi males. (S, 6 Oktober 2014)

Mengatakan bahwa tidak semua praktek religius harus diketahui orang lain, tidak hanya disampaikan S tapi juga E sebagai berikut: 
Saya pasang aplikasi waktu sholat di smartphone, tapi tidak diberi penanda adzan..karena saya juga tidak ingin orang lain tahu atau terganggu bahwa saya menggunakan aplikasi itu..cukup saya aja yang tahu bahwa ketika bunyi "ting" oh itu udah masuk waktu sholat... [saat wawancara ada bunyi ting pada saat waktu dhuhur]..waktu sholat untuk pengetahuan pribadi saya aja...konteksnya toleransi juga...saya gak mau orang lain terganggu ketika dalam suatu acara atau pembicaraan tiba-tiba terdengar bunyi adzan dari SP saya..menurut saya itu global manner ya...Islam itu harus luwes, ramah...(E, 3 Januari 2015)

Tidak hanya Odoj komunitas beribadah virtual yang dibentuk melalui smartphone. Adapula komunitas Kutub, yaitu komunitas sholat tahajud dan dhuha bersama. Hampir sama seperti Odoj, komunitas ini akan membentuk kelompok dimana setiap anggota akan diberikan pengingat (reminder) ketika waktu sholat tahajjud dan dhuha tiba. Anggota komunitas juga harus memberikan laporan setiap mereka selesai melaksanakan kedua sholat sunnah tersebut. Sebagaimana Odoj, komunitas sholat tahajjud dan dhuha ini pun mengandung kontroversi. Tidak semua kaum muslim sepakat dengan praktek beragama seperti ini, karena rentan sekali dengan keterpaksaan dan perilaku riya (pamer).

\section{Identitas Virtual, Ketika Panggung Depan dan Panggung Belakang Menyatu}

Tampak jelas bahwa, seperti halnya dengan praktek penggunaan smartphone lainnya, beragama melalui smartphone pun tidak lepas dari ambivalensi. Kehadiran smartphone di satu sisi telah memudahkan para penggunanya untuk menjalankan ritual keagamaan mereka. Di sisi lain tidak sedikit aplikasi keagamaan berhenti hanya pada tataran simbol belaka. Memiliki aplikasi kitab suci di smartphone tidak lantas membuat para penggunanya membaca kitab suci tersebut setiap saat ketika mereka memiliki waktu luang. Membuka media sosial tetap lebih sering dilakukan daripada membuka kitab suci. Demikian pula dengan memasang aplikasi waktu sholat tidak serta merta membuat para pengguna smartphone dengan serta merta pula melaksanakan ibadah sholat saat aplikasi tersebut mengingatkan mereka bahwa waktu sholat telah tiba. Perilaku beragama yang ditunjukkan melalui smartphone hakikatnya tidak dapat serta merta dipercaya kebenarannya. Identitas religius yang dikonstruksi melalui smartphone ibarat sebuah tampilan di panggung depan (front stage) yang telah diatur sedemikian rupa sehingga seringkali tidak diketahui aslinya seperti apa. Sebuah identitas shalehah virtual, dimana gambaran tentang perilaku beragama seseorang hanya kita pahami dari potongan gambar yang disajikan melalui smartphone. Terkait dengan hal ini, Hackett (2006: 73) mengatakan bahwa, "In the shifting world of virtuality and hypertextuality, the parameters of the real/ unreal/ hiyperreal/ surreal are indeterminate. Identities can be assumed and manipulated in all shorts of creative and destructive ways."

Di sisi lain, tidak semua identitas virtual adalah identitas yang palsu. Bisa terjadi, ruang display yang tersedia di smartphone justru digunakan oleh penggunanya untuk menampilkan "diri" mereka yang sesungguhnya. Layar smartphone adalah back stage bagi sebagian orang. Karakteristik smartphone yang terkoneksi dengan internet memberikan peluang pembebasan kepada penggunanya, khususnya perempuan, untuk mengekspresikan diri yang mungkin selama ini tertutup peluangnya di dunia nyata. Bagi perempuan yang selama ini seringkali mengalami kondisi represif dan subordinatif, peluang yang ditawarkan smartphone tentu saja sangat menarik. Sebagaimana yang dikatakan oleh $\mathrm{E}, \mathrm{R}$ dan $\mathrm{S}$ berikut, 
Saya bukan orang yang religius, tetapi ketika saya memutuskan bahwa saya akan menggunakan hijab maka saya akan berusaha untuk konsisten dengan keputusan itu termasuk untuk tidak tampil terbuka di smartphone maupun semua social media yang saya miliki. (E, 3 Januari 2015).

Di sisi lain, meski $\mathrm{E}$ konsisten dengan pilihannya untuk tampil tertutup, Ejuga rajin menampilkan aktivitas dirinya yang beragam. E memiliki mobilitas yang cukup tinggi, dan sering mengikuti berbagai konferensi di luar negeri. Melalui identitas yang dibangunnya secara tidak langsung $\mathrm{E}$ ingin mengatakan bahwa pilihannya berpenampilan, statusnya yang seorang hajjah, bukanlah hambatan bagi seorang perempuan untuk bisa beraktivitas dan berprestasi. Selain E, R yàng seorang shalaffy juga memanfaatkan smartphone untuk menjangkau ruang lain dari kehidupannya yang tidak dapat dia raih sebagai seorang shalaffy.

Saya itu shalaffy mbak, tapi gaul hehe...saya pake BBM, WhatsApp, Instagram. Selain info agama saya juga suka browsing resep masakan di internet. Dulu saya pake laptop tapi sekarang udah jarang, sekarang pake smartphone aja, lebih praktis. Saya juga menyimpan banyak kontak di smartphone saya, baik di BBM, WA, nomor telepon, laki-laki juga ada...pokoknya yang saya anggap bermanfaat ya saya simpan. ( $R, 9$ Desember 2014)

$R$ yang sehari-hari selalu menggunakan baju berwarna gelap dengan jilbab panjang dan bercadar mengaku bahwa pergaulannya dalam dunia nyata sangat terbatas. Tidak saja dengan lawan jenis bahkan banyak perempuan yang masih berprasangka terhadap perempuan shalaffy seperti dirinya. Melalui smartphone, $\mathrm{R}$ ingin menunjukkan bahwa pilihannya untuk menjalankan ajaran Islam shalaffy tidak membuatnya menjadi pribadi yang tertutup sama sekali. R mengaku bahwa banyak pengikut shalaffy yang mengharamkan hiburan, musik, televisi dan sejenisnya, namun kehadiran internet dan smartphone ternyata mampu membawa perubahan pada sebagian pengikut shalaffy termasuk dirinya. Dengan berpegang pada niat untuk menggunakan teknologi komunikasi secara positif, $\mathbf{R}$ pun menjadikan smartphone sebagai bagian dari kehidupannya.

Menggunakan smartphone dan media sosial sebagai alat resistensi terhadap identitas religius yang dilekatkan pada perempuan, juga dilakukan oleh $M$. Sebagai satu-satunya pendeta perempuan di kotanya, $M$ merasa ia seperti hidup dalam aquarium. Semua orang menuntutnya untuk tampil ideal sebagai pendeta dengan identitas esensialis yang mereka pahami, termasuk untuk berpenampilan secara bersahaja. Di sisi lain, $M$ mengaku bahwa dia sangat menyukai fashion. M memutuskan untuk tampil sebagai diri yang dia inginkan tetap fashionable namun dia juga menyertai publikasi tentang dirinya di media sosial dengan beragam aktivitas yang dia lakukan sebagai pendeta. $M$ ingin mengatakan bahwa penampilan dirinya bukanlah ukuran religiusitas ataupun profesionalitas dia sebagai pendeta perempuan.

Sampai pada tataran ini, proses transformasi agama dan beragama yang digerakkan oleh kehadiran smartphone tidaklah secara serta merta dapat dijustifikasi sebagai sebuah kemunduran atau sesuatu yang negatif. Smartphone hanya menawarkan sebuah alternatif dari praktek beragama yang ada. Beragama melalui smartphone bisa menjadi sekedar bagian dari gaya hidup sebagaimana dikatakan Giddens bahwa setiap orang dalam masyarakat modern pasti dan harus memilih gaya hidup. "Lifestyle is not only about fancy jobs and conspicuous consumption, though, the term applies to wider choices, behaviors, and to (to greater or lesser degrees) attitudes and beliefs" (dalam Gauntlet, 2002: 102). Namun di sisi lain, beragama melalui smartphone juga bisa memberikan 
alternatif untuk menjalankan praktek beragama yang sebelumnya ada.

\section{Simpulan}

Smartphone dengan karakteristik
yang dimilikinya, telah mampu
mendorong tumbuhnya praktek baru
beragama yang dijalankan dengan logika
smartphone. Smartphonisasi agama
tersebut mewarnai hampir semua praktek
beragama mulai dari pencarian dan
penyebaran informasi keagamaan, praktek
ritual keagamaan, hingga pada

pembentukan habitus keagamaan dan bahkan resistensi atas identitas religius yang dilekatkan pada diri perempuan urban.

Smartphonisasi agama tidak serta merta dapat dijustifikasi sebagai sebuah kemunduran atau bahkan pencemaran atas kesakralan agama. Ambivalensi yang melekat pada smartphone dengan sendirinya juga akan menawarkan peluang yang bisa membawa transformasi positif maupun negatif pada penggunanya, termasuk di dalam menjalankan praktek beragama.

\section{Daftar Pustaka}

Campbell, Heidi A. 2011. "Understanding the Relationship between Religion Online and Offline in Networked Society." Dalam Journal of the American Academy of Religion. Hal. 1-30

Foltz, Franz dan Foltz, Frederick. 2003. "Religion on The Internet: Community and Virtual Existence" dalam Bulletin of Science Technology Society, Vol. 23. Nomor 4. Agustus 2003. Hal. 321330

Gauntlett, David. 2002. Media, Gender, and Identity. London \& New York: Routledge

Hackett, Rosalind I. J. 2006. Religion and the Internet. Dalam Diogenes 211 halaman $67-76$.
Hjarvard, Stig. 2006. The Mediatization of Religion, A Theory of the Media as an Agent of Religious Change. Paper. Dipresentasikan dalam the $5^{\text {th }}$ International Conference on Media, Religion and Culture: Mediating Religion in the Context of Multicultural Tension. Sweden, 6-9 Juli 2006

Moulin, Daniel. 2013. "Negotiating and Constructing Religious Identities". Paper. Disampaikan dalam REA Annual Meeting, 8-10 November 2013

Possamai, Adam. 2005. Religion and Popular Culture, A Hyper - Real Testament. Brussels: P.I.E - Peter - Lang 